Published by Al-Nahrain College of Medicine P-ISSN 1681-6579

E-ISSN 2224-4719

Email: iraqijms@colmed-alnahrain.edu.iq

http://www.colmed-alnahrain.edu.iq

http://www.iraqijms.net

Iraqi JMS 2018; Vol. 16(4)

\title{
The Efficacy and Safety of Percutaneous Nephrolithotomy in Correlation with Different Renal Stone Burdens
}

\author{
Issam S. Al-Azzawi ${ }^{1}$ FICMS, FEBU, Ali W. Mohammed Zaki ${ }^{1}$ FICMS, Hader I. Jwaid ${ }^{2}$ FICMS, Samir L. \\ Salih² FICMS, Ali A. Al-Obaidi² FICMS
}

${ }^{1}$ Dep.t of Urology, College of Medicine, Al-Mustansiriyah University, Baghdad, Iraq, ${ }^{2}$ Dep.t of Urology, Al-Yarmouk Teaching Hospital, Baghdad, Iraq

\section{Abstract}

Background The improvements in instruments and technique of percutaneous nephrolithotomy (PCNL) in the last 3 decades have led to expansion in its indications to include even the large and complex renal stone cases.

Objective

Methods To determine the efficacy and safety of PCNL in relation to stone complexity.

In this prospective, clinical, interventional study, 51 patients with symptomatic renal stones of different sizes and locations, were admitted in our Urology Unit, fully evaluated and treated by our team with PCNL. For all the patient's data collected were: age, gender, body mass index (BMI), previous renal surgery, pre-operative stone number, stone size, stone position, stone opacity, surgical approach, operative time, stone clearance rate, postoperative residual stones and complications, hospital stay and adjuvant therapy. By using different statistical methods, correlations were made to elicit the impact of stone size, stone position, stone opacity, $\mathrm{BMI}$ and previous renal surgery, operative time, stone free rate, complication rate and the need for auxiliary procedures.

Results In this study, the 51 included patients were 31 males and 20 females with a mean age 40.3 year. All the stones treated were over $2 \mathrm{~cm}$ in their longest diameter, with $58.8 \%$ of them were $\geq 3 \mathrm{~cm}$, and mean stone size was $4.2 \pm 0.99 \mathrm{~cm}$. The most prevalent site of stone was the lower calyx $(39.2 \%)$, followed by $(37.3 \%)$ as partial staghorn, while complete staghorn calculi constituted (11.8\%). The final success rate of treatment was $86.3 \%$. $(60.8 \%)$ of the cases found to be stone free at immediate postoperative period. Auxiliary procedures were used in (27.5\%) patients, to improve the stone clearance. Residual stones were ultimately remained in only (7.8\%). Complications occurred in 11 patients (21.6\%).

Conclusion PCNL though demanding, is an effective and reasonably safe procedure for the treatment of different renal stone burdens. Size and position of stones in the calyceal system and past renal surgery were the main determinants of operative time, stone clearance, complication rate and the need for auxiliary procedures.

Keywords

Citation Renal stone, PCNL, stone complexity, stone free rate, complications

Al-Azzawi IS, Mohammed Zaki AW, Jwaid HI, Salih SL, Al-Obaidi AA. The efficacy and safety of percutaneous nephrolithotomy in correlation with different renal stone burdens. Iraqi JMS. 2018; 16(4): 385-392. doi: 10.22578/IJMS.16.4.5

List of abbreviations: $\mathrm{BMI}=$ Body mass index, $\mathrm{CT}=$ Computerized tomography, ESWL = Extracorporeal shock wave lithotripsy, IVU = Intravenous urography, $\mathrm{PCNL}=$ Percutaneous nephrolithotomy, UPJ = Uretero-pelvic junction, URS = Ureteroscopy

\section{Introduction}

$\mathrm{T}$ There are many factors that should be considered in dealing with renal stones including; stone size, position, chemical composition, hardness of stone, presence of a distal obstruction, renal function indices, availability of equipment and experience of the surgeon. All these factors will dictate the type of therapy suitable for each patient. Current treatment options for renal stones are extra corporeal shock wave lithotripsy (ESWL), percutaneous nephrolithotomy (PCNL), retrograde intra renal surgery (RIRS), and to 
much less extent open surgery. In addition to preventive medical treatment ${ }^{(1-3)}$.

Since the first PCNL procedure described by Fernstro and Johansson in $1976{ }^{(4)}$, till now, there was a dramatic improvement in all aspects of this procedure including the type of nephroscope used, the fluoroscopy localization technique, the intracorporeal lithotripters used (including the Holmium laser), and the camera system ${ }^{(5)}$. These improvements in instruments and technique have led to expansion in the indications of PCNL to include even the large and complex renal stone cases. Current indications for PCNL includes: Staghorn calculi, large stone burden $(>2 \mathrm{~cm})$, hard calculi (cystine, brushite, struvite, calcium oxalate monohydrate), impacted or large proximal ureteral calculi, calyceal diverticular calculi, ectopic renal calculi (as in horseshoe kidney, pelvic kidney, or transplanted kidney), Coexisting Uretero-pelvic junction (UPJ) obstruction and renal calculi, Lower pole renal calculi greater than $1 \mathrm{~cm}$, and stones that have failed ESWL ${ }^{(6)}$.

Preoperative planning is essential to identify the position and number of stones, assess the intrarenal collecting system architecture, and to evaluate the relationship of the kidney and its surrounding organs. This is achieved by using one or more imaging modalities; as plain radiograph (KUB), renal ultrasonography, intravenous urography (IVU), and computerized tomography (CT) scan (7).

Difficult Access Situations included: previous renal surgery, perinephric scarring, supracostal upper calyx, mobile kidney, calyceal diverticulum, inability to find the renal pelvis, bifid collecting system, non-dilated collecting system, horseshoe kidney and pelvic kidney ${ }^{(8)}$. The aim of the study was to determine the efficacy and safety of PCNL in relation to stone complexity (according to different patient and stone parameters).

\section{Methods}

In this prospective clinical interventional study, which was conducted during the period
(November 2014 to November 2016), 51 patients with symptomatic renal stone disease, treated with PCNL in our center, were included. Inclusion criteria were patients above 18 years of age, irrespective of gender with normal renal function and stone size $>2 \mathrm{~cm}$.

Exclusion criteria were untreated active urinary tract infection, uncorrected coagulopathy, severe cardiovascular disease, pregnancy, severe obesity and patients with congenital renal anomalies (such as horseshoe or ectopic kidneys).

For all the patient's data were collected: age, gender, BMI, previous renal surgery, preoperative stone number, stone size, stone position, stone opacity, surgical approach, operative time, stone clearance rate, postoperative residual stones \&complications, hospital stay and adjuvant therapy.

In addition to history, clinical examination and routine laboratory Investigations, preoperative imaging with KUB, renal ultrasonography and CT scan were used to identify the number, size, opacity and location of stones and the anatomical details of the collecting system. IVU sometimes used when CT scan not available. Stone positions were classified into:

- Upper or middle calyx

- Pelvic or lower calyx

- Partial staghorn

- Complete staghorn

All patients were treated under general anesthesia, in prone position and a single subcostal lower pole percutaneous access was usually made by using the "triangulation" technique under fluoroscopic guidance. Then rigid nephroscopy was performed and stones were localized and fragmented by a pneumatic lithotriptor. Normal saline was used for continuous irrigation by using pulsatile lowpressure perfusion pump.

At the completion of fragmentation, stones were removed with grasping forceps. Stone clearance and the integrity of the collecting system were confirmed intraoperatively by nephroscope and fluoroscopy.

Finally, a $5 \mathrm{Fr}$ Double-J stent was introduced antegradely into the ureter and a $16 \mathrm{Fr}$ 
nephrostomy tube (Foley catheter) was inserted into the renal pelvis or the involved calyx at the conclusion of the procedure. Nephrostomy tube usually removed after 24 hours if there is no urine leakage, pain, fever or residual stone and in the absence of any complications, the patient usually discharged on the second postoperative day.

When residual calculi larger than $8 \mathrm{~mm}$ were present, ESWL or a second PCNL was considered after 2 weeks. All complications (intraoperative and postoperative) were stated. Stone free state is defined as the absence of any visible stone fragments on the nephroscopy at the end of the procedure and on the early postoperative imaging studies.

The final success rate is defined as the absence of significant stone fragments on the postoperative imaging studies after 6 weeks.

Statistical analysis was conducted by using the Statistical Package for Social Sciences (SPSS) version 20. The continuous data were represented by mean, standard deviation and range, while the categorical data presented as frequency and percentage tables. P-Value < 0.05 was used as the alpha level of significance. This study was approved by the ethical committee of our hospital and all the patients signed an informed consent.

\section{Results}

In this prospective clinical interventional study, out of the 51 patients included; 31 (60.8\%) were males and 20 (39.2\%) were females, their mean age was 40.3 years and ranged from (1862 ) years.

The mean body mass index of the patients was $22.9 \pm 2.7 \mathrm{~kg} / \mathrm{m}^{2}$ and ranged from 18 to 28 , about one-fourth (13/51) of them were overweight $\left(\geq 25 \mathrm{~kg} / \mathrm{m}^{2}\right)$. The study also showed that 15 out of 51 included patients (29.4\%) have previous renal surgeries.

Regarding the stone characteristics in the included patients, as shown in table $1,39 / 51$ (76.5\%) were radio-opaque, and 30/51 (58.8\%) of the managed renal stones were $(\geq 3 \mathrm{~cm})$ with mean stone size $4.2 \pm 0.99 \mathrm{~cm}$.
The most prevalent site of stone was the lower calyx; 20/51 (39.2\%), followed by $19 / 51$ (37.3\%) as partial stag-horns occupying the pelvis \& one of the calyces. Hydronephrosis was found to be mild in 22 (43.1\%), moderate in 18 (35.3\%) and only 3 (5.9\%) had a severe grade (Table 1 ).

In this study, the final success rate of treatment was $86.3 \%$ (in 44 patients) and that $31 / 51$ $(60.8 \%)$ of the cases found to be stone free at immediate postoperative period. Auxiliary procedures were used in 14 (27.5\%) patients, to improve the stone clearance, including 6 patients underwent ESWL, 4 patients treated by URS and staged PCNL was done in 4 patients. Residual stones were ultimately remained in only $4 / 51$ (7.8\%).

Conversion to open surgery was only needed in three $(5.9 \%)$ patients. Complications occurred in 11 patients (21.6\%), with no fatal or lifethreatening complications (Table 2).

The operative time of PCNL procedure was found to be different and correlated with certain patients \& stone characteristics. Factors that significantly affect the operative time were: stone size $(p<0.0001)$, the position of the stone $(p<0.0001)$ and previous renal surgery $(p=0.014)$ (Table 3$)$.

Stone free rate was also correlated \& significantly higher among patients with small size stones (95.2\%), in lower calyx stones $(100 \%)$ and in patients with no previous renal surgery $(72.2 \%)$, as shown in table 4.

The postoperative complications were found to be significantly associated with only the stone size as $(36.7 \%)$ of patients with large size stones $(\geq 3 \mathrm{~cm})$ showed complications while no one of the patients with small size stones had any complication $(p=0.005)$.

Other parameters like patients' BMI, past renal surgical history, stone position and opacity did not show significant associations with postoperative complications in our series.

The need for the use of auxiliary procedures (to accomplish stone clearance) was also significantly associated with: the size of the stones $(p=0.007)$ (being used in $43.3 \%$ of 


\section{Al-Azzawi et al, Percutaneous Nephrolithotomy}

patients with large stones in comparison to $4.8 \%$ among those with stones $(<3 \mathrm{~cm})$, with the complexity of stone position $(p<0.0001)$ (the auxiliary procedures were needed in $33.3 \%, 36.8 \%$ and $83.3 \%$ in upper calyx, partial and complete staghorn stones respectively ) and were much more needed in patients with previous renal surgery $(60 \%)$ with a $P$ value 0.002 .

The conversion to open surgery was done in only $3(5.9 \%)$ cases, without any significant correlation with any of the studied parameters.

Table 1. Renal stone Characteristics in the included patients

\begin{tabular}{ccc}
\hline Variables & Number & Percent \\
\hline Stone location & & \\
Right & 29 & $56.9 \%$ \\
Left & 22 & $43.1 \%$ \\
Right: Left ratio & $1.32: 1$ & \\
\hline Opacity & & \\
Lucent & 12 & $23.5 \%$ \\
Opaque & 39 & $76.5 \%$ \\
Opaque: Lucent ratio & $3.25: 1$ & \\
Size & & $41.2 \%$ \\
$<3$ cm & 21 & $58.8 \%$ \\
$\geq 3$ cm & 30 & $39.2 \%$ \\
Position & & $37.3 \%$ \\
Lower calyx & 20 & $11.8 \%$ \\
Partial stag-horn & 19 & $11.8 \%$ \\
Upper calyx & 6 & \\
Complete stag-horn & 6 & $15.7 \%$ \\
Grade of Hydronephrosis & & $43.1 \%$ \\
No & 8 & $35.3 \%$ \\
Mild & 22 & $5.9 \%$ \\
Moderate & 18 & \\
Sever & 3 &
\end{tabular}

Table 2. Number and percentage of complications in PCNL patients

\begin{tabular}{ccc}
\hline Variables & Number & Percent \\
\hline Fever $>38{ }^{\circ} \mathrm{C}$ & 9 & $17.6 \%$ \\
Urine leakage (pcs extravasation) & 7 & $13.8 \%$ \\
Bleeding requiring transfusion & 6 & $11.8 \%$ \\
Visceral injury (pneumothorax) & 1 & $2.0 \%$ \\
\hline
\end{tabular}


Iraqi JMS 2018; Vol. 16(4)

Table 3. Correlation of mean operative time with renal stone's and patient characteristics

\begin{tabular}{ccc}
\hline Variables & $\begin{array}{c}\text { Operation duration (Minute) } \\
\text { Mean } \pm \text { Standard deviation }\end{array}$ & p-value \\
\hline Stone size & $83 \pm 12$ & $<0.0001^{*}$ \\
$<3 \mathrm{~cm}$ & $102 \pm 16$ & \\
$\geq 3 \mathrm{~cm}$ & $92 \pm 15$ & \\
\hline Positiona & $98 \pm 12$ & \\
Upper calyx & $123 \pm 14$ & \\
Partial staghorn & $83 \pm 11$ & 0.275 \\
Complete staghorn & & \\
Lower calyx & $90 \pm 13$ & \\
\hline Opacity & $95 \pm 18$ & 0.585 \\
Lucent & & \\
Opaque & $93 \pm 18$ & \\
\hline BMI & $96 \pm 15$ & \\
$<25$ kg/m2 & $102 \pm 13$ & \\
$\geq 25$ kg/m2 & $91 \pm 18$ & \\
\hline Yes & &
\end{tabular}

Independent t-test, a ANOVA test, * Significant at 0.05 level

Table 4. Correlation of the stone-free rate with renal stone's and patient characteristics

\begin{tabular}{|c|c|c|c|}
\hline \multicolumn{4}{|c|}{ Stone free rate } \\
\hline Variables & $\begin{array}{c}\text { Yes } \\
\text { No. (\%) }\end{array}$ & $\begin{array}{c}\text { No } \\
\text { No. (\%) }\end{array}$ & p-value \\
\hline \multicolumn{4}{|l|}{ Stone size $^{Y}$} \\
\hline$<3 \mathrm{~cm}$ & $20(95.2)$ & $1(4.8)$ & \multirow{2}{*}{$<0.0001^{*}$} \\
\hline$\geq 3 \mathrm{~cm}$ & $11(36.7)$ & $19(63.3)$ & \\
\hline \multicolumn{4}{|l|}{ Position $\mathrm{E}$} \\
\hline Upper calyx & $3(50)$ & $3(50)$ & \multirow{4}{*}{$<0.0001^{*}$} \\
\hline Partial stag-horn & $7(36.8)$ & $12(63.2)$ & \\
\hline Complete stag-horn & $1(16.7)$ & $5(83.3)$ & \\
\hline Lower calyx & $20(100)$ & $0(0)$ & \\
\hline \multicolumn{4}{|l|}{ Opacity $^{Y}$} \\
\hline Lucent & $9(75)$ & $3(25)$ & \multirow{2}{*}{0.415} \\
\hline Opaque & $22(56.4)$ & $17(43.6)$ & \\
\hline \multicolumn{4}{|l|}{ BMI $\chi$} \\
\hline$<25 \mathrm{~kg} / \mathrm{m}^{2}$ & $26(68.4)$ & $12(31.6)$ & \multirow{2}{*}{0.056} \\
\hline$\geq 25 \mathrm{~kg} / \mathrm{m}^{2}$ & $5(38.5)$ & $8(61.5)$ & \\
\hline \multicolumn{4}{|l|}{ Previous renal surgery $\chi$} \\
\hline Yes & $5(33.3)$ & $10(66.7)$ & \multirow{2}{*}{$0.01 *$} \\
\hline No & $26(72.2)$ & $10(27.8)$ & \\
\hline
\end{tabular}

Y Yates continuity correction of chi, E Exact test, ${ }^{\chi}$ Chi-square tests, * Significant at 0.05 level. 


\section{Discussion}

The goal of surgical therapy for renal stones is to achieve maximum stone clearance with the least morbidity to the patient. Percutaneous access to the renal collecting system with improvement of endourologic instruments and intra-corporeal lithotripters has yielded greater success rates and lower complication rates and is therefore recommended as the treatment of choice for renal stones measuring $>2 \mathrm{~cm}$ in diameter ${ }^{(9)}$.

Nevertheless, PCNL considered a demanding procedure and it is only safe and effective in experienced hands ${ }^{(10)}$.

Currently, complex staghorn calculi have been mostly managed with PCNL. The morbidity of PCNL in this aspect is less than open surgery with better stone-free rates (11). In fact, staghorn calculi were the most difficult group of stones treated in this series with the least immediate stone-free rate (16.7\%). It is known that PCNL for the treatment of staghorn stones is a challenging procedure. It requires considerable experience in gaining percutaneous tracts, performing delicate and judicious intrarenal manipulations, mastering all techniques of intracorporeal stone disintegration, and weighing the benefits of complete stone clearance against the risks of complications ${ }^{(12)}$.

The mean operative time in our study was 102 minutes for stone size $(\geq 3 \mathrm{~cm})$, which is longer than in other studies (Shalaby et al, 80 minutes) ${ }^{(13)}$. This could be attributed to the difference in experience, facilities \& completeness of stone clearance.

A significant positive correlation was seen between stone burden and operative time, because larger stone need more time for fragmentation, as well as the position of the stone significantly affects the operation duration, being the longest in complete staghorn stones (occupying the whole pelvicalyceal system) and shortest in lower calyx stones. Access to the other calyces can be difficult through the subcostal route by rigid nephroscope. In our experience, access through a lower calyx into the upper and middle calyx was difficult and necessitates longer operative and fluoroscopy time.
The overall stone-free rate in our study at the time of hospital discharge was $60.8 \%$ and increased to $86.3 \%$ by using auxiliary procedures postoperatively. This rate is lower than that reported by Rahman's study (83\% $90.8 \%)^{(14)}$ and higher than that reported by ElNahas et al study (56.6\%-72.7\%) (12).

PCNL should aim to achieve maximum stone clearance. The reasons for residual fragments are migration of a stone or stone fragments to an inaccessible calyx, termination of the procedure because of bleeding, complex anatomy increasing the technical difficulty, and inability to visualize the stone on fluoroscopy.

The judicious use of auxiliary procedures (repeated PCNL, URS, ESWL) in the early postoperative period for removal of clinically significant stone fragments will improve the final stone clearance rate. Moreover, the combined use of rigid and flexible nephroscope (when available) facilitate stones retrieval through calyces that could not be negotiated by rigid nephroscope alone and the use of the flexible Holmium YAG laser fibers through flexible nephroscope will help in-situ disintegration of calyceal stones and improved the overall success rate $(12,15)$.

Stone free cases in our series were significantly higher among patients with small size stones and those located in one calyx (especially the lower calyx) because in such size \& position there is less possibility of having residual fragments. While in staghorn stones with multiple large branches, percutaneous access to all the calyces was somehow difficult through one tract, that's why the rate of residual stones was high.

In this study, the overall complication rate was $21.6 \%$, which is lower than in Mousavi's study $(30.3 \%)^{(16)}$. Fever was recorded in 9 (17.6\%) patients, and all were treated conservatively with good antibiotics cover and delaying the withdrawal of the nephrostomy tube till the fever subsided. Transient post- operative fever occurs in up to $30 \%$ of patients after PCNL, which is usually related to duration of surgery and the amount of irrigation fluid used, but the rate of sepsis is much lower, ranging from $0 \%$ to $3 \%$ in patients covered with appropriate perioperative antibiotics ${ }^{(17)}$. 
Bleeding requiring blood transfusion has been reported to be $1 \%$ to $15 \%{ }^{(6)}$. It occurred in 6 $(11.8 \%)$ of our patients, with an average perioperative blood loss of $950 \mathrm{ml}$ (estimated by calculating the blood content in the sucker bottle \& the drainage bag), which is higher than in Rahman's study (4.8\%) ${ }^{(14)}$. The risk of hemorrhagic complications requiring blood transfusion in our study was associated with a larger tract size (for large stones), renal pelvic perforation, and total blood loss. In most of the cases the bleeding was controlled by placement of the nephrostomy tube and/or clamping the nephrostomy tube to tamponade the bleeding, but in 2 cases the procedure was converted to open surgery.

In PCNL, the overall pleural injury rate with supra-costal access was estimated to be $16 \%$, compared to $4.5 \%$ with an infra-costal approach, and as many as $64 \%$ of patients with pleural injury require chest tube drainage (17).

The only visceral injury in this series was a Pneumothorax which occurred in one (2\%) patient, due to very highly placed kidney under the rib cage, which is comparable to the rate of pleural injury in Ullah's study (1.9\%) ${ }^{(9)}$. This injury was successfully treated by a thoracostomy drain but the procedure converted to open one.

The postoperative complications were found to be significantly associated with stone size as there was a tendency to higher grade complications in complex stones, which was similar to the findings in Abdelhafez's study (10), because dealing with large stones need prolonged operative time, larger volumes of irrigation fluid and difficult manipulation with a higher possibility of perforation and bleeding $(18,20)$.

PCNL in a patient with previous renal surgery may take longer duration and lead to a higher percentage of auxiliary procedures ${ }^{(8,19)}$, as in the current study, probably because of the scar tissue and anatomic changes in the kidney that lead to difficulties in tract dilation of perinephric space, in addition, intrarenal manipulation of stone will be more difficult.

This study concluded that PCNL, though demanding, is an effective and reasonably safe procedure for the treatment of different renal stone burdens.

In this study, size and position of stones in the calyceal system and past renal surgery were the main determinants of operative time, stone clearance, complication rate and the need for auxiliary procedures.

\section{Acknowledgments}

The authors express their gratitude for all the staff of the urology department of Al-Yarmouk teaching hospital for their substantial help.

\section{Author Contribution}

All authors have made substantial contributions to this study: Dr. Al-Azzawi: study concept and design, general supervision on the work, critical revision and final approval of the manuscript. Dr. Mohammed Zaki and Dr Salih: acquisition of data, analysis and interpretation of data, and drafting the manuscript. All 5 authors contributed in patient selection, admission, performing the surgical procedures, follow up and data collection for the patients included in this study.

\section{Conflict of interest}

Authors declare no conflict of interest.

\section{Funding}

There was no funding source for this research.

\section{References}

1. Srisubat A, Potisat S, Lojanapiwat B, et al. Extracorporeal shock wave lithotripsy (ESWL) versus percutaneous nephrolithotomy (PNL) or retrograde intrarenal surgery (RIRS) for kidney stones. Cochrane Database Syst Rev. 2014; issue 11. Art. No.: CD007044. doi: 10.1002/14651858.CD007044.pub3.

2. Alkan E, Ozkanli O, Avci E, et al. Effectiveness of flexible ureterorenoscopy and laser lithotripsy for multiple unilateral intrarenal stones smaller than $2 \mathrm{~cm}$. Adv Urol. 2014; article ID 314954, 5 pages. doi: http://dx.doi.org/10.1155/2014/314954.

3. Kenney PA, Wotkowicz C, Libertino JA. Contemporary open surgery of the kidney. In: Kavoussi LR, Novick AC, Partin AW, et al (eds). Campell-Walsh urology. $10^{\text {th }}$ ed. Vol 2. Philadelphia: Elsevier Saunders; 2012. p. 1554-1627.

4. Spann A, Poteet J, Hyatt D, et al. Safe and effective obtainment of access for percutaneous nephrolithotomy by urologists: the Louisiana State 
University Experience. J Endourol. 2011; 25(9): 14215. doi: 10.1089/end.2010.0643.

5. Patel SR, Nakada SY. The modern history and evolution of percutaneous nephrolithotomy. J Endourol. 2015; 29(2): 153-7. doi: 10.1089/end.2014.0287.

6. Miller N, Lingeman JE. Percutaneous renal access. In: Smith JA, Howards SS, McGuire EJ, et al (eds). Hinman's atlas of urologic surgery. $3^{\text {rd }}$ ed. Philadelphia: Elsevier Saunders; 2012. p. 845-53.

7. Yuhico MP, Ko R. The current status of percutaneous nephrolithotomy in the management of kidney stones. Minerva Urologica Nefrologica. 2008; 60: 159-75.

8. Marcovich R, Smith AD. Percutaneous renal access: tips and tricks. BJU Int. 2005; 95: 78-84. doi: 10.1111/j.1464-410X.2005.05205.x.

9. Ullah $A$, Khan $M K$, Rahman $A U$, et al. Percutaneous nephrolithotomy: A minimal invasive surgical option for the treatment of staghorn renal calculi. Khyber Med Univ J. 2012; 4(4): 156-60.

10. Abdelhafez MF, Bedke J, Amend B, et al. Minimally invasive percutaneous nephrolithLapaXY (PCNL) as an effective and safe procedure for large renal stones. BJU Int. 2012; 10(11 Pt C): E1022-6. doi: 10.1111/j.1464-410X.2012.11191.x.

11. Desai $M$, Jain $P$, Ganpule A, et al. Developments in technique and technology: the effect on the results of percutaneous nephrolithotomy for staghorn calculi. BJU Int. 2009 Aug;104(4):542-8; discussion 548. doi: 10.1111/j.1464-410X.2009.08472.x.

12. El-Nahas AR, Eraky I, Shokeir AA, et al. Percutaneous nephrolithotomy for treating staghorn stones: 10 years of experience of a tertiary-care centre. Arab J Urol. 2012; 10(3): 324-9. doi: 10.1016/j.aju.2012.03.002.

13. Shalaby MM, Abdalla MA, Aboul-Ella HA, et al. Single puncture percutaneous nephrolithotomy for management of complex renal stones. BMC Res Notes. 2009; 2: 62. doi: 10.1186/1756-0500-2-62.

14. Rahman AU, Ullah $A$, Khan $S$, et al. Percutaneous nephrolithotomy for the treatment of renal stones larger than $2.5 \mathrm{~cm}$. JPMI: J Postgrad Med Instit. 2011; 25: 362-7.

15. Stoller ML. Urinary Stone Disease. In: McAninch JW, Lue TF. Smith \& Tanagho's General urology. 18th ed. New York: McGraw-Hill; 2013. p. 249-79.

16. Mousavi-Bahar SH, Mehrabi S, Moslemi MK. Percutaneous nephrolithotomy complication in 671 consecutive patients: a single-center experience. Urol J. 2011; 8(4): 271-6.

17. Taylor E, Miller J, Chi T, et al. Complications associated with percutaneous nephrolithotomy. Transl Androl Urol. 2012; 1(4): 223-8. doi: 10.3978/j.issn.2223-4683.2012.12.01.

18. Akman T, Sari E, Binbay $M$, et al. Comparison of outcomes after percutaneous nephrolithotomy of staghorn calculi in those with single and multiple accesses. J Endourol. 2010; 24(6):955-60. doi: 10.1089/end.2009.0456.

19. Khorrami MH, Hadi M, Sichani MM, et al. Percutaneous nephrolithotomy success rate and complications in patients with previous open stone surgery. Urol J. 2014; 11(3): 1557-62.

20. De S, Autorino R, Kim FJ, et al. Percutanous nephrolithotomy versus Retrograde intrarenal surgery: a systematic review and meta-analysis. Eur Urol. 2015; 67(1): 125-37. doi: 10.1016/j.eururo.2014.07.003.

Correspondence to Dr. Issam S. Al-Azzawi
E-mail: issam_alazzawi@yahoo.com
Received Nov. $1^{\text {st }} 2017$
Accepted Apr. $1^{\text {st }} 2018$

